\title{
A phase II prospective study of the "Sandwich" protocol, L-asparaginase, cisplatin, dexamethasone and etoposide chemotherapy combined with concurrent radiation and cisplatin, in newly diagnosed, I/II stage, nasal type, extranodal natural killer/T-cell Iymphoma
}

\author{
Ming Jiang ${ }^{1, *}$, Li Zhang ${ }^{1,4, *}$, Li Xie ${ }^{2, *}$, Hong Zhang ${ }^{2}$, Yu Jiang ${ }^{1}$, Wei-Ping Liu ${ }^{3}$, Wen- \\ Yan Zhang ${ }^{3}$, Rong Tian ${ }^{5}$, Yao-Tiao Deng ${ }^{1}$, Sha Zhao ${ }^{3}$ and Li-Qun Zou ${ }^{1}$ \\ ${ }^{1}$ Department of Medical Oncology, State Key Laboratory, Cancer Center, West China Hospital of Sichuan University, Chengdu, \\ China \\ ${ }^{2}$ Radiation Oncology of Cancer Center, West China Hospital of Sichuan University, Chengdu, China \\ 3 Pathology Department, West China Hospital of Sichuan University, Chengdu, China \\ ${ }^{4}$ Department of Oncology, Dujiangyan Medical Center, Dujiangyan, Sichuan, China \\ ${ }^{5}$ Department of Nuclear Medicine, West China Hospital of Sichuan University, Chengdu, China \\ * These authors have contributed equally to this work \\ Correspondence to: Li-qun Zou, email: zliqun@hotmail.com \\ Keywords: nasal-type, extranodal NK/T cell lymphoma, L-asparaginase, cisplatin, etoposide and dexamethasone (LVDP) \\ Received: June 19, $2016 \quad$ Accepted: January 27, $2017 \quad$ Published: March 17, 2017
}

Copyright: Jiang et al. This is an open-access article distributed under the terms of the Creative Commons Attribution License 3.0 (CC BY 3.0), which permits unrestricted use, distribution, and reproduction in any medium, provided the original author and source are credited.

\section{ABSTRACT}

Nasal-type, extranodal NK/T cell lymphoma (ENKTCL) is a special type of lymphomas with geographic and racial specificity. Up to now, the standard first-line treatment is still not unified. In our previous report, the "sandwich" protocol produced good results. Continuing to use the "sandwich" mode, a new chemotherapy composed of L-asparaginase, cisplatin, etoposide and dexamethasone (LVDP) plus concurrent chemoradiotherapy (CCRT) was conducted in more patients with newly diagnosed, I/ II stage ENKTCL. The results showed that 66 patients were enrolled. Overall response rate was $86.4 \%$ including $83.3 \%$ complete response and $3.0 \%$ partial remission. With the median follow-up of $\mathbf{2 3 . 5}$ months, 3-year overall survival and 3-year progressionfree survival were $70.1 \%$ and $67.4 \%$, respectively. The survival rate in stage II and extra-cavity stage I was significantly less than that in limited stage I $(p<0.05)$. Therefore, we thought that the "sandwich" mode was worthy of being generalized and LVDP combined with CCRT was an effective protocol for I/II stage ENKTCL. But this regimen was not suitable for all stage I/II patients and warrants larger sample and layering investigation. This study was a registered clinical trial with number ChiCTR-TNC-12002353.

\section{INTRODUCTION}

Nasal-type, extranodal NK/T cell lymphoma (ENKTCL) is a special type of non-Hodgkin's lymphoma, which is rare in Europe and North America, but relatively common in Asia and South America [1, 2]. In China, the incidence of ENKTCL is higher and secondary to diffuse large B cell lymphoma, accounting for about
$11 \%$ of all lymphomas [3]. About $60-90 \%$ of ENKTCL derive from nasal cavity and its adjacent sites and up to $75 \%$ of patients have I/II Ann Arbor stage at the initial diagnosis $[4,5]$. However, traditional therapy based on anthracyclines achieved unsatisfied effect- 5 -year overall survival (OS) rate is less than $50 \%[2,6]$. Chemotherapy composed of non-anthracycline drugs showed superior effect [7-9], especially L-asparaginase-based regimens 
which are the mainstream choice. But the optimal chemotherapy, the way of chemotherapy combined with radiotherapy and the dose of radiation are still undefined. In our previous report, the "sandwich" protocol, 2 cycles of systemic chemotherapy made up of L-asparaginase, vincristine and prednisone (LVP) were followed by sequential radiotherapy with $56 \mathrm{~Gy}$ and supplemented with 2-4 cycles of LVP, achieved good improvement and mild side effects [10] indicated that the "sandwich" protocol deserves further research in I/II stage ENKTCL patients.

In order to improve the efficacy and further study on "sandwich" regimen, we designed and administrated a new chemotherapy regimen including L-asparaginase (L-ASP), cisplatin, etoposide and dexamethasone (LVDP) combined with concurrent radiation and cisplatin. A prospective clinical study was conducted in more patients with newly diagnosed, I/II stage ENKTCL. The primary end points of this study: (1) short term efficacy (overall response rate (ORR), complete response (CR), (2) 3-year progress-free survival (PFS) and OS. The secondary endpoints: short term side effects.

\section{RESULTS}

\section{Basic characteristics}

Sixty-six ENKTCL patients with newly diagnosed, stage I/II were enrolled. Basic characteristics were shown in Table 1 . The median age was $41.5 \mathrm{y}$ (rang: 13 to $70 \mathrm{y}$ ). There were 44 male patients with 2.0 times as many as the female (22 cases). 14 cases $(21.2 \%)$ were in limited IE stage, $29(43.9 \%)$ in extra-cavity IE stage and $23(34.8 \%)$ in IIE stage. Twenty- five cases $(37.9 \%)$ had B symptom. Twenty- three $(34.8 \%)$ had regional lymph nodes invasion. According to the NK/T cell lymphoma international prognostic index (NKIPI) [11], 25 patients (37.9\%) were 0 score, 22 patients $(33.3 \%)$ were 1 score, 16 patients $(24.2 \%)$ were 2 score and 3 patients $(4.5 \%)$ were 3 score.

\section{Response}

A total of 336 cycles of chemotherapy ( 4.8 cycles in average, 1-6 cycles) were administrated, pegaspargase was used in 50 cycles of them. 59 patients $(89.4 \%)$ received 4-6 cycles of chemotherapy. 7 patients $(10.6 \%)$ had 1-3cycles of chemotherapy. Chemotherapy was stopped in one patient due to the onset of pancreatitis after 3 cycles. Two refused to continue chemotherapy after 3 courses. 4 patients' treatments, because of disease progression, were terminated, 2 of whom died soon and 2 received second-line therapy. The patients completed radiotherapy according to schedule, except the two died early. After two-cycle chemotherapy and CCRT, 51 cases had CR (77.3\%), 10 had partial response (PR) (15.2\%) and the ORR was $92.4 \%$. At the end of therapy, 55 had CR $(83.3 \%), 3$ had PR (3.0\%) and the ORR was $86.4 \%$. These were shown in Figure 1.

\section{Survival}

The 66 patients were followed up until April 2015. As shown in Figure 1, 13.6\% (9/66) experienced disease progression during the therapy period including 1 local progression and 8 system failure. 13 of 55 (23.6\%) patients with $\mathrm{CR}$ experienced recurrence. Among of them, two patients $(3.6 \%)$ experienced relapses in the previous radiation field, and eleven (20\%) experienced systemic recurrence, with five in skin soft tissue (one with pulmonary metastasis and one with liver and bone metastasis), two in bone marrow (one with splenic metastasis), one in lung, two in gastrointestinal tract and one in the central nervous system. Only one of these thirteen patients survived at the deadline of follow-up, living with stable condition after second-line chemotherapy. Eleven patients didn't achieve CR after first-line treatment. Up to the end of follow-up, 8 of them died $(8 / 11,72.7 \%)$ and $3(3 / 11,27.3 \%)$ survived. With the median follow-up of 23.5 months (range: 12 to 51 months), a total of $22(33.3 \%)$ had disease progression including $4.5 \%$ for local failure and $28.8 \%$ for systemic failure. For patients who had disease progression, their median survival was 15 months. For whole group, the 3 -year OS rate was $70.1 \%$ (Figure 2A), and the 3-year PFS rate was $67.4 \%$ (Figure $2 \mathrm{~B}$ ), the median OS had not been reached.

\section{Toxicity}

As shown in Table 2, the most common toxicity was that patients were allergic to L-ASP (45.5\%). Among of them, $3.0 \%$ with negative skin test underwent slight allergic reaction including skin rash and itching, and recovered soon after stopping the infusion, administrating hormone and calcium. Hematological toxicities were also common during chemotherapy, but most of them were mild. 11 patients $(16.7 \%)$ had grade 3 or 4 leukopenia and 2 patients $(3.0 \%)$ had grade 3 thrombocytopenia. Severe non-hematologic toxicities included two patients $(3.0 \%)$ with grade 3 vomiting and one (1.5\%) with pancreatitis. Toxicities were minimal during CCRT, with 4 patients (6.1\%) showing grade 3 radiation-related mucositis and $1(1.5 \%)$ with grade 3 radiation-related dermatitis. There was no treatment-related death.

\section{DISCUSSION}

Radiotherapy and chemotherapy are both important for treatment of ENKTCL. Radiotherapy specialists agree that early or 'up-front' radiotherapy improves the ORR and 
Table 1: Basic characteristics of the patients

\begin{tabular}{|c|c|}
\hline Characteristics & Number of patients (\%) \\
\hline $\begin{array}{l}\text { Age, } y \text { (median, range, } 41.5(13-70)) \\
<60 \\
\geq 60\end{array}$ & $\begin{array}{c}58(87.9) \\
8(12.1)\end{array}$ \\
\hline $\begin{array}{l}\text { Sex } \\
\text { Male } \\
\text { Female }\end{array}$ & $\begin{array}{l}44(66.7) \\
22(33.3)\end{array}$ \\
\hline $\begin{array}{l}\text { ECOG Score } \\
0 \\
1 \\
2\end{array}$ & $\begin{aligned} 45 & (68.2) \\
20 & (30.3) \\
1 & (1.5)\end{aligned}$ \\
\hline $\begin{array}{l}\text { Stage } \\
\text { Limited IE } \\
\text { Extra-cavity IE } \\
\text { IIE }\end{array}$ & $\begin{array}{l}14(21.2) \\
29(43.9) \\
23(34.8)\end{array}$ \\
\hline $\begin{array}{l}\text { Serum LDH } \\
\text { Normal } \\
\text { Increase }\end{array}$ & $\begin{array}{l}47(71.2) \\
19(28.8)\end{array}$ \\
\hline $\begin{array}{l}\text { "B" symptom } \\
\text { No } \\
\text { Yes }\end{array}$ & $\begin{array}{l}41(62.1) \\
25(37.9)\end{array}$ \\
\hline $\begin{array}{c}\text { IPI } \\
0 \\
1\end{array}$ & $\begin{array}{l}41(62.1) \\
25(37.9)\end{array}$ \\
\hline $\begin{array}{c}\text { NKIPI } \\
0 \\
1 \\
2 \\
3\end{array}$ & $\begin{array}{c}25(37.9) \\
22(33.3) \\
16(24.2) \\
3(4.5)\end{array}$ \\
\hline $\begin{array}{l}\text { Regional lymph nodes metastasis } \\
\text { No } \\
\text { Yes }\end{array}$ & $\begin{array}{l}43(65.2) \\
23(34.8)\end{array}$ \\
\hline $\begin{array}{l}\text { Perforation } \\
\text { No } \\
\text { Yes }\end{array}$ & $\begin{array}{c}60(90.9) \\
6(9.1)\end{array}$ \\
\hline $\begin{array}{l}\text { Platelet count } \\
\text { Normal } \\
\text { Decrease } \\
\text { Increase } \\
\end{array}$ & $\begin{aligned} 51 & (77.3) \\
4 & (6.1) \\
11 & (16.7)\end{aligned}$ \\
\hline $\begin{array}{l}\text { Lymphocyte count } \\
\text { Normal } \\
\text { Decrease } \\
\text { Increase }\end{array}$ & $\begin{array}{c}52(78.8) \\
12(18.2) \\
2(3.0)\end{array}$ \\
\hline $\begin{array}{l}\text { CSWOG staging* } \\
\text { I } \\
\text { II } \\
\text { III }\end{array}$ & $\begin{array}{l}18(27.3) \\
26(39.4) \\
22(33.3)\end{array}$ \\
\hline
\end{tabular}

ECOG, Eastern Cooperative Oncology Group; LDH, Lactic dehydrogenase; IPI, International Prognostic Index; NKIPI, NK/T-cell lymphoma International Prognostic Index;

*Extranodal NK/T-cell lymphoma, nasal-type new staging system by Chinese Southwest Clinical Oncology Group (CSWOG) (http://meetinglibrary.asco.org/content/128647-144 ) 


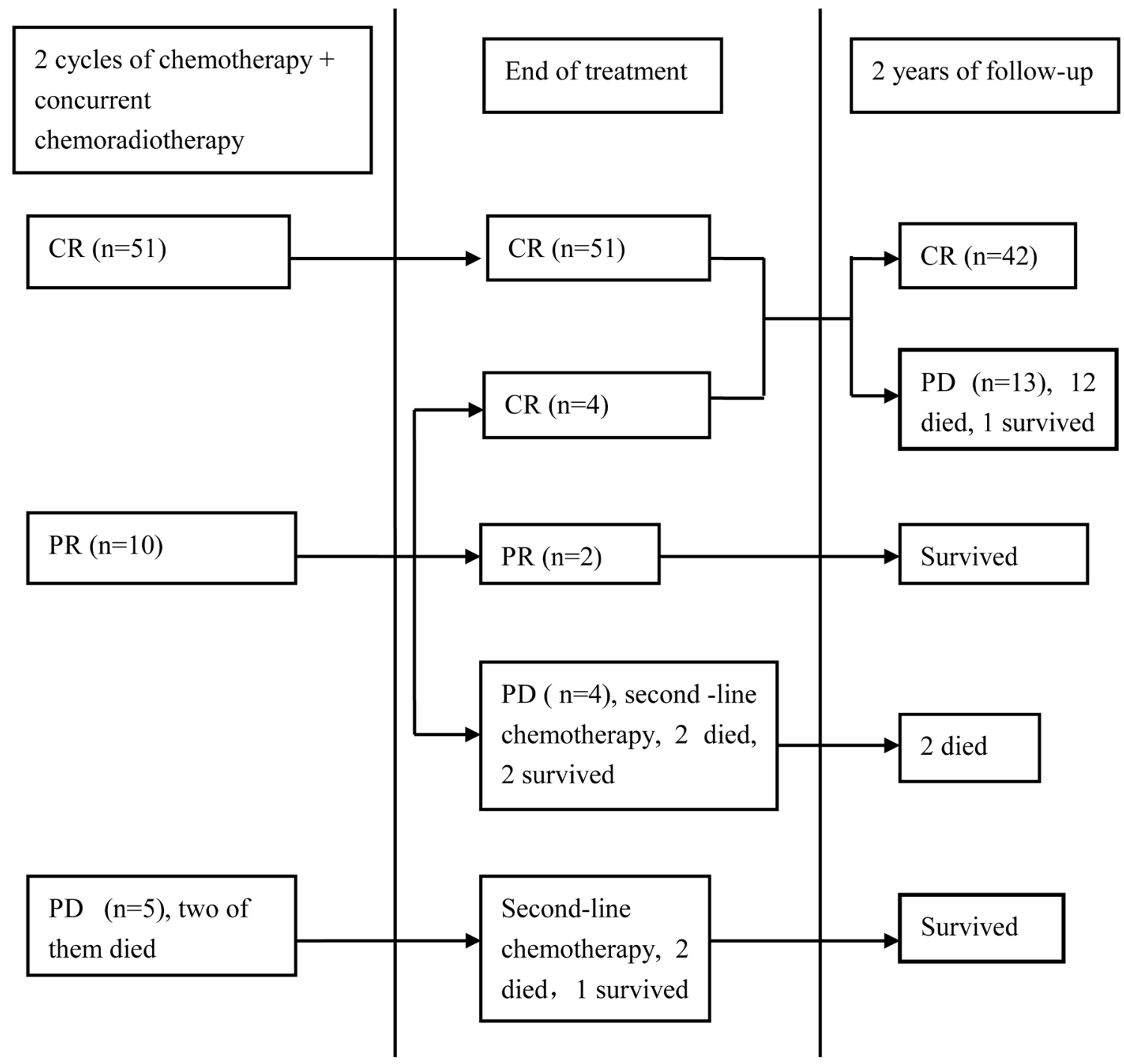

Figure 1: Treatment response and prognosis in patients. (CR complete response, PR partial response, PD progressive disease).
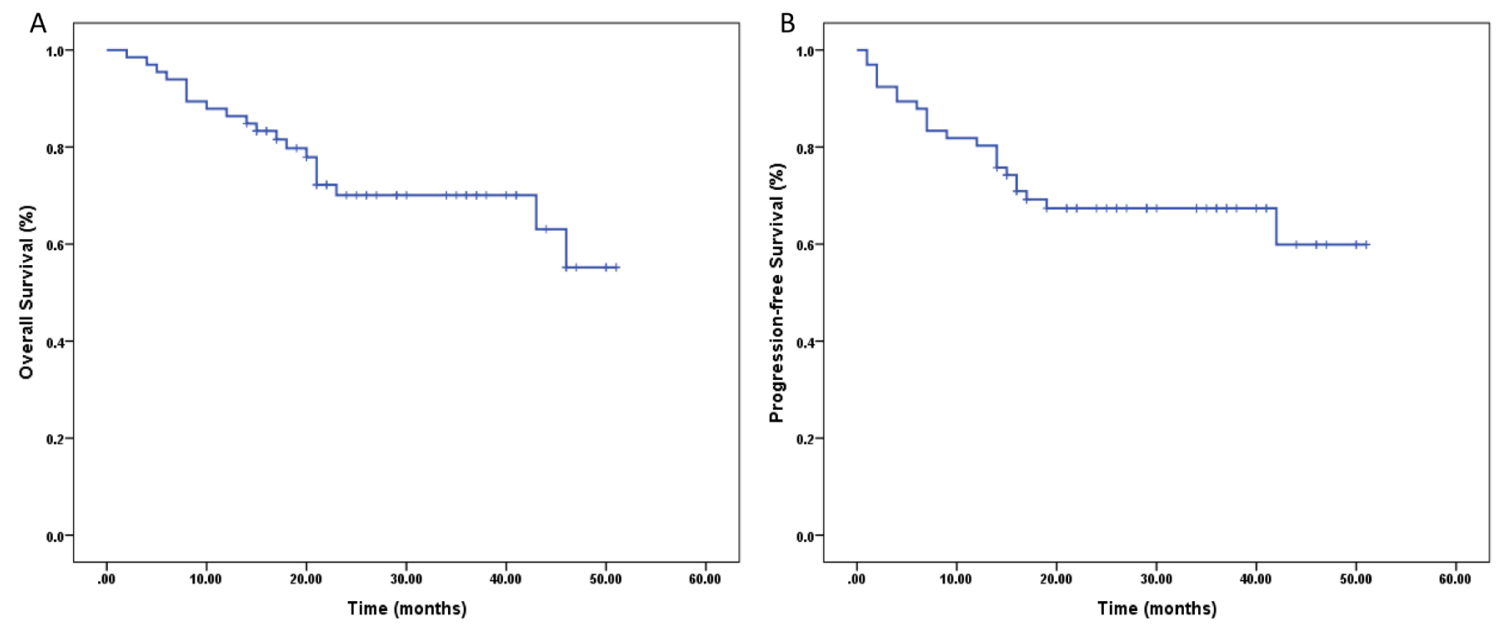

Figure 2: Survival curves. A., Overall survival for all patients. B., Progression-free survival for all patients. 
Table 2: Toxicity observed during therapy

\begin{tabular}{|c|c|c|c|c|}
\hline Toxicity & Grade1 (N.\%) & Grade $2\left(N_{.} \%\right)$ & Grade $3(N . \%)$ & Grade $4(N . \%)$ \\
\hline $\begin{array}{l}\text { Hematological toxicity } \\
\text { Anemia } \\
\text { Leukocytopenia } \\
\text { Thrombocytopenia }\end{array}$ & $\begin{array}{l}17(25.7 \%) \\
20(30.3 \%) \\
14(21.2 \%)\end{array}$ & $\begin{array}{l}7(10.6 \%) \\
12(18.2 \%) \\
6(9.1 \%) \\
\end{array}$ & $\begin{array}{l}1(1.5 \%) \\
6(9.1 \%) \\
2(3.0 \%) \\
\end{array}$ & \begin{tabular}{|l}
0 \\
$5(7.6 \%)$ \\
0 \\
\end{tabular} \\
\hline $\begin{array}{l}\text { Non-hematological toxicity } \\
\text { Nausea } \\
\text { Vomiting } \\
\text { Diarrhea } \\
\text { Hepatic dysfunction } \\
\end{array}$ & $\begin{array}{l}32(48.5 \%) \\
22(33.3 \%) \\
2(3.0 \%) \\
2(3.0 \%) \\
\end{array}$ & $\begin{array}{l}4(6.1 \%) \\
5(7.6 \%) \\
0 \\
1(1.5 \%) \\
\end{array}$ & $\begin{array}{l}0 \\
2(3.0 \%) \\
0 \\
0\end{array}$ & $\begin{array}{l}0 \\
0 \\
0 \\
0\end{array}$ \\
\hline Pancreatitis & $1(1.5 \%)$ & & & \\
\hline Skin test positive/Allergy & $30(45.5 \%)$ & & & \\
\hline $\begin{array}{l}\text { Radiation-related mucositis } \\
\text { Radiation-related dermatitis }\end{array}$ & $\begin{array}{l}18(27.3 \%) \\
20(30.3 \%) \\
\end{array}$ & \begin{tabular}{|l|}
$37(56.1 \%)$ \\
$34(51.5 \%)$ \\
\end{tabular} & \begin{tabular}{|l|}
$4(6.1 \%)$ \\
$1(1.5 \%)$ \\
\end{tabular} & \begin{tabular}{|l}
0 \\
0 \\
\end{tabular} \\
\hline
\end{tabular}

Table 3: Clinical trials regarding to first-line chemoradiotherapy in I/II stage NK/T lymphoma

\begin{tabular}{|c|c|c|c|c|c|c|c|c|}
\hline Study & Staging & \begin{tabular}{|l|}
$\begin{array}{l}\text { No.of } \\
\text { patients }\end{array}$ \\
\end{tabular} & Treatment regimen & ORR (\%) & CR (\%) & OS (\%) & PFS (\%) & $\begin{array}{l}\text { Grade } 3 / 4 \text { toxicity } \\
(\%)\end{array}$ \\
\hline Wang et al. [15] & $\begin{array}{l}\mathrm{IE}=18 \\
\mathrm{IIE}=9\end{array}$ & 27 & \begin{tabular}{|ll}
$\begin{array}{l}\text { GELOX } \\
\text { radiation }\end{array}$ & plus \\
\end{tabular} & 96.3 & 74.4 & $86(2-y)$ & $86(2-y)$ & $\begin{array}{l}\text { Hematologic } 33.3 \\
\text { Mucositis } 15\end{array}$ \\
\hline Kim et al. [16] & $\begin{array}{l}\mathrm{I}=15 \\
\mathrm{II}=15\end{array}$ & 30 & \begin{tabular}{|l} 
Concurrent \\
chemoradiotherapy \\
plus VIPD
\end{tabular} & 100 & 73.3 & $86.3(3-y)$ & $85.2(3-y)$ & $\begin{array}{l}\text { Neutrocytopenia } 40 \\
\text { Nausea } 3\end{array}$ \\
\hline $\begin{array}{l}\text { Yamaguchi et al. } \\
\text { [17] }\end{array}$ & $\begin{array}{l}\mathrm{IE}=22 \\
\mathrm{IIE}=11\end{array}$ & 27 & DeVIC plus radiation & 81 & 77 & $78(2-y)$ & $67(2-y)$ & \begin{tabular}{|l|} 
Leukocytopenia 97 \\
Neutrocytopenia 91 \\
\end{tabular} \\
\hline Jiang et al. [18] & $\begin{array}{l}\mathrm{IE}=13 \\
\text { Extended } \mathrm{IE} \\
=7 \\
\mathrm{IIE}=6\end{array}$ & 26 & LVP plus radiation & 88.5 & 80.8 & $88.5(2-y)$ & $80.6(2-y)$ & $\begin{array}{l}\text { Leukocytopenia } 7.7 \\
\text { Mucositis } 23.1\end{array}$ \\
\hline This study & $\begin{array}{l}\mathrm{IE}=14 \\
\text { Extended IE } \\
=29 \\
\mathrm{IIE}=23\end{array}$ & 66 & $\begin{array}{l}\text { VDLP plus } \\
\text { Concurrent } \\
\text { chemoradiotherapy }\end{array}$ & 86.4 & 83.3 & $70.1(3-y)$ & $67.4(3-y)$ & \begin{tabular}{|l} 
Leukocytopenia \\
16.7 \\
Thrombocytopenia \\
3.0
\end{tabular} \\
\hline
\end{tabular}

ORR, objective response rate; CR, complete response; OS, overall survival; PFS, progression-free survival.

OS. Meanwhile, early chemotherapy is important as well as radiotherapy, because distant metastasis is the main reason inducing treatment failure [7-9, 12, 13]. It is well known that ENKTL resistance to anthracycline, the mechanisms may be related to the high expression of P-glycoprotein by lymphoma cells [14]. Therefore, anthracycline-based treatment did not achieve satisfied effect. Some novel regimes containing non-anthracycline drugs such as L-asparaginase or pegaspargase, cisplatin, oxaliplatin, ifosfamide, methotrexate, etoposide, gemcitabine and dexamethasone showed superior effect in ENKTCL [7-9]. However, the optimal regimen is still undefined. The protocols suggested by National Comprehensive Cancer Network Clinical Practice Guidelines include concurrent chemoradiation therapy (CCRT), sequential chemoradiation, sandwich chemoradiation and RT alone for patients unfit for chemotherapy. Some clinical trials including our previous research resulted $[10,15,16]$ that "sandwich" chemoradiation was a promising protocol. We carried out a new regimen which was LVDP combined with CCRT, the "sandwich" protocol, in I/II stage patients aimed to discuss the optimal treatment. To our knowledge, our study is the largest prospective study regarding to treatment of newly diagnosed, I/II stage ENKTCLs.

In this study, 66 patients with stage I/II were enrolled. At the end of therapy, CR was $83.3 \%$, PR was $3.0 \%$ and the ORR was $86.4 \%$. The median follow-up was 23.5 months, with 3-year PFS of $67.4 \%$, and 3-year OS of $70.1 \%$. The median OS has not been reached. Compared with several previous prospective clinical studies focused on I/II stage ENKTCL patients [7-10] (Table 3), our results showed that short term response was similar with others. However, either 3-year OS or 3-year PFS was inferior. Through detailed comparison, we found that this difference may be due to: 1) the previous four studies had far smaller sample size than our study, which were in greater likelihood of bias; 2) The survival of patients with stage II and extra-cavity stage I were significantly worse than that of patients with limited stage I, while the survival difference between stage II and extra-cavity stage I was not statistically significant (Figure $3 \mathrm{~A}$ and $3 \mathrm{~B}$ ). In present study, the patients with stage II and extra-cavity I accounted for $78.8 \%$. However, the above-mentioned study carried by Wang et al. [7], Kim et al. [8] and Yamaguchi et al. [9] did not subdivide the stage I patients into limited I and extra-cavity I, with the phase II patients 
accounting for 33\%, 50\% and 33\%, respectively. Even in our previous research, the proportion of extra-cavity phase I and phase II was only 50\% [10]. This indirectly indicated that Ann Arbor stage system did not guide a better stratification for ENKTCL patients' survival.

In addition, there are many other factors affecting prognosis. JY Lee and colleagues concluded NKIPI model composed of 'B' symptoms, stage, lactate dehydrogenase (LDH) level and regional lymph nodes, which could better predict prognosis [11]. SJ Kim et al. developed PINK model consisted of four risk factors (age, stage, non-nasal type, and distant lymph-node involvement) that were significantly associated with OS and PFS in ENKTCL [17]. In recent years, peripheral blood EBV-DNA copy number has been considered as a prognostic factor and related to therapeutic effect of ENKTCL patients [18, 19]. And now it is a routine laboratory test item at diagnosis, during treatment and following-up. Due to the limitation of laboratory conditions, it was tested in a small number of patients who were included in the late period of this study. Therefore, it was not involved in this report. However, the research about prognostic factors and prognosis system is in progress, and the results would be reported in subsequent paper.

Radiotherapy plays an irreplaceable role for cancer treatment. Usually, increasing the dose of radiotherapy might improve efficacy, while the radiotherapy-associated complications are increasing as well. For ENKTCL, the radiation dose is controversial. We reviewed literatures and found that it was variety in different clinical center, the range was from 40 to $65 \mathrm{~Gy}[8,13]$. In the study of Wang $\mathrm{H}$ et al, the prescribed dose of 50Gy was planned with a boost of 5-10Gy to the residual primary disease, while the dose which the patients actually received was from 49.6
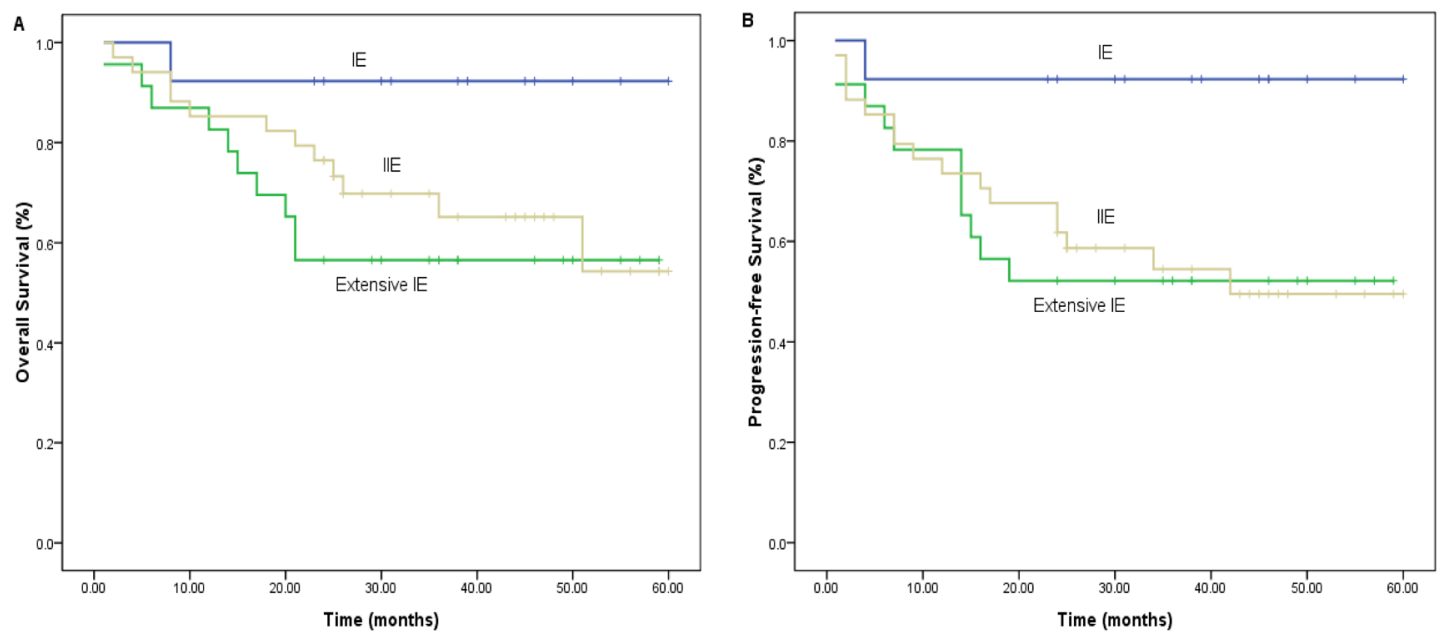

Figure 3: Analysis of prognostic value of Ann Arbor staging, A. (for OS) and B. (for PFS).

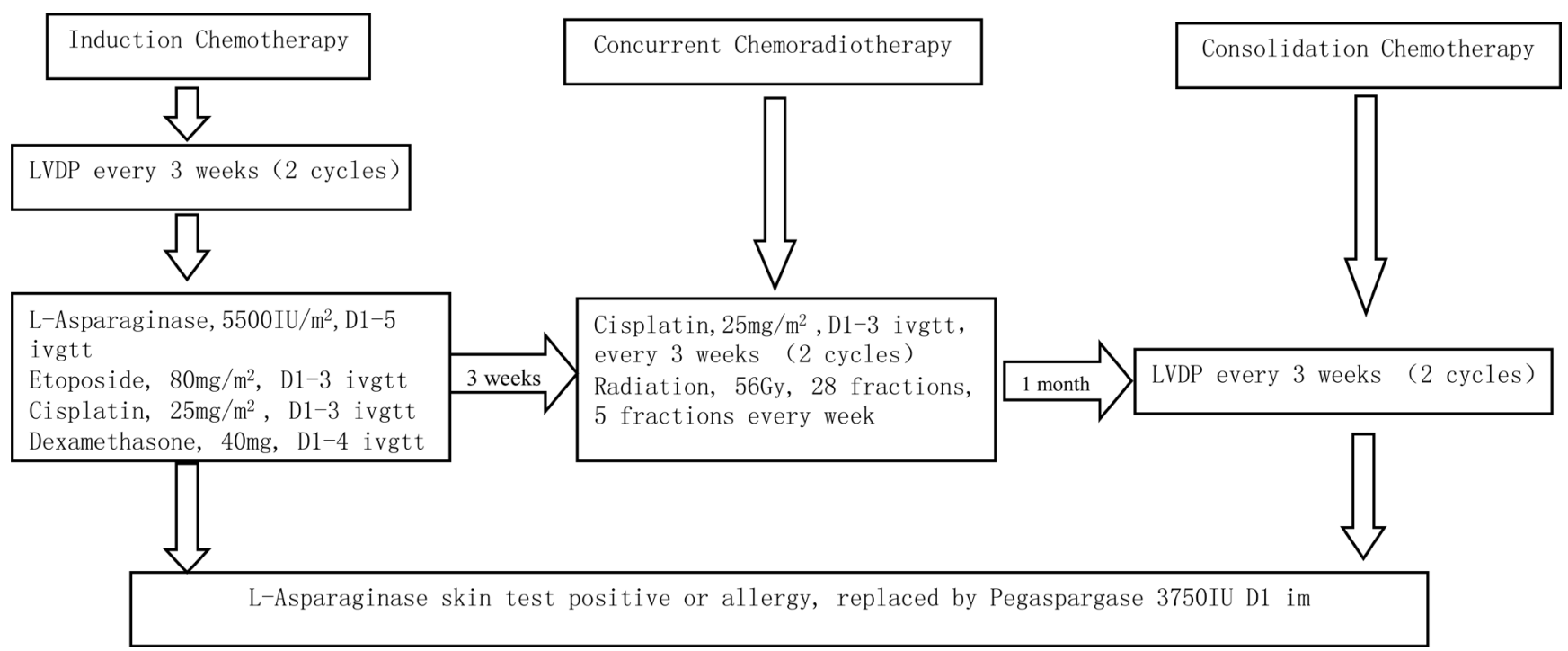

Figure 4: Treatment protocol. 
Gy to $64 \mathrm{~Gy}$, mean dose was $55.5 \mathrm{~Gy}$ [20]. Our previous study suggested that dose of 56 Gy achieved local-control rate and toxicities were tolerated [10]. In this study, we continued to execute our previous radiotherapy protocol, it also showed good local control and was tolerated.

In present study, the total failure rate was $33.3 \%$ (22 cases), with $4.5 \%$ for local failure and $28.8 \%$ for systemic failure. Although they received second-line treatment, their median OS was only 15 months, which was far short compared with the whole patients' OS (23.5 months). In other words, the majority of failure was systemic that caused poor OS. This consisted with the other researches' results that most patients died soon after disease progression [7-9, 12, 13]. In addition, no matter using radiotherapy alone or CCRT, the rate of local failure was low and could be remedied. Compared with literature reports [7-10], although cisplatin was used to sensitize the radiotherapy, the benefits of local control and survival were not observed in this study. Therefore, the efficacy of systemic therapy was a significant factor impacting prognosis of I/II stage ENKTCLs. The value of CCRT still needs future research.

In this study, both hematologic and non-hematologic toxicities during therapy were lighter than reported results [7-9] and heavier than LVP [10]. But they were well tolerance. Pancreatitis caused by L-ASP should be worth paying more attention, because it can lead to seriously consequence, even death. In this study, one patient suffered acute pancreatitis in the third cycle of chemotherapy. After treatment, the patient's condition got improved and was still alive in disease-free situation at the end of following up. Through comprehensive assessment, we found that he had a history of chronic pancreatitis with significantly elevated serum triglyceride level. Therefore, light diet is recommended during therapy, especially in patients with a history of pancreatic disease or elevated blood lipids.

In summary, for the treatment of I/II stage ENKTCLs, the "sandwich" protocol is worthy of being generalized and LVDP combined with CCRT is an effective regimen with well tolerated toxicity. But this regimen was not suitable for all phase I/II patients and the value of CCRT needs further research. Therefore, in future studies, we will carry out larger sample and layering study for first-line therapy. In addition, another limitation about this study is that it was a single-institutional study. So a multi-centric collaborative study will be needed.

\section{PATIENTS AND METHODS}

\section{Inclusion criterion}

1) The ENKTCL patients were diagnosed based on pathological histology and immunohistochemistry, meeting the WHO criteria. 2) The patients with I/II stage.
3) Primary tumor located in the upper aerodigestive tract. 4) The patients received no radiotherapy or chemotherapy for ENKTCL. 5) White blood cell (WBC) $\geq 3,500 / \mathrm{ul}$, absolute neutrophil count (ANC) $\geq 1,000 /$ ul, platelet $(\mathrm{PLT}) \geq 75,000 / \mathrm{ul}$, glutamic-pyruvic transaminase (ALT) and glutamic oxalacetic transaminase $($ AST $)<2.5$ times the upper limit of the normal level (ULN), total bilirubin $<2.0 \mathrm{mg} / \mathrm{dL}$, creatinine clearance $(\mathrm{Cr}) \geq 50 \mathrm{ml} /$ minute. 6 ) Eastern Cooperative Oncology Group (ECOG) score of 0 to 2. 6) Expected survival time $>3$ months. 7) Patients voluntarily participated and signed the informed consent.

\section{Exclusion criteria}

1) Women during pregnancy or lactation. 2) Any clinical problems beyond our control (such as serious mental, nervous, cardiovascular and respiratory system diseases). 3) The researchers considered that the patient is not appropriate to participate.

This study was registered in www.chictr.org.cn at 5/30/2012 and approved by the Chinese Ethics Committee of Registering Clinical Trials. The registration number: ChiCTR-TNC-12002353. The research was carried out in West China Hospital, Sichuan University. The methods were carried out based on the protocols recommended by National Comprehensive Cancer Network Clinical Practice Guidelines (NCCN Guidelines) and metabolic pathways of drugs in vivo.

\section{Protocol}

The treatment scheme was shown in Figure 4. Chemotherapy was started within 7 days after registration. The drugs' doses and administration schedule were as follows: L-asparaginase $5500 \mathrm{IU} / \mathrm{m}^{2}$ given intravenously on days 1 through 5 , etoposide $80 \mathrm{mg} / \mathrm{m}^{2}$ given intravenously on day 1 through 3 , cisplatin $25 \mathrm{mg} / \mathrm{m}^{2}$ given intravenously on days 1 through 3 , and dexamethasone $40 \mathrm{mg}$ /day given intravenously on days 1 through 4 . The enrolled patients first received 2 cycles of LVDP as induction chemotherapy, followed by CCRT with radiation and 2 cycles of cisplatin alone. A month later, 2 cycles of LVDP were administrated for consolidating. Before using L-ASP at each cycle, skin test was performed. If the skin test was positive or the patients appeared allergic reaction caused by transfusing L-ASP, it was replaced by spegaspargase (3750 IU, D1) with intramuscular injection at three sites.

Routine blood test (RBT), liver and kidney function were tested before each cycle. The patient was not allowed to enter the next course until $\mathrm{ANC} \geq 1,000$ / $\mathrm{ul}$, PLT $\geq 75,000 / \mathrm{ul}$ and ALT and AST $<2.5$ times of ULN. One to two RBT were performed every week during chemotherapy intermission. Granulocyte colonystimulating factor (G-CSF) was administered if the patient 
developed grade 3/4 neutropenia. Grade 4 leukopenia or neutropenia happened first after chemotherapy, G-CSF was prophylactic administered in the following cycles. If grade 4 leukopenia or neutropenia happened again or grade 4 thrombocytopenia appeared, the dose of cisplatin and etoposide were reduced to $75 \%$ of initial dose during subsequent cycles. If $3 / 4$ grade of toxicity persisted $>2$ weeks, the patient was excluded.

Radiotherapy was scheduled after 2 cycles LVDP. Intensity modulated radiation therapy (IMRT) or threedimensional conformal radiation therapy (3D-CRT) was used. Radiotherapy targets included gross tumor volume (GTV), clinical tumor volume (CTV) and planning target volume (PTV). GTV are the lesions evaluated by imaging and clinical examination. CTV is defined as the entire anatomical structure where the tumor infiltrates (CTV1) and the adjacent tissue structures where the tumor may get involved (CTV2). PTV is $3-5 \mathrm{~mm}$ wider than GTV or CTV in three dimensions. The dose of GTV or CTV1 was 50-56Gy and CTV2 was 45-50.4Gy. Stage II patients whose primary site was nasal cavity and Webster ring needed prophylactic bilateral neck irradiation, with the dose of 45Gy. The irradiation was given in routine dose fraction, namely daily dose was 1.8-2.0Gy, one time a day, five times one week. Radiotherapy was delayed in patients with the following situations: grade 4 leukopenia or neutropenia; PLT $<25,000 / \mathrm{uL}$; any grade 3 mucositis and dysphagia associated with radiation; ECOG score $\geq$ 3 . Radiotherapy would be hold until the toxicity resolved to $\leq 2$. If the grade $3 / 4$ toxicity persisted $>2$ weeks, the protocol was terminated.

\section{Evaluation}

Two weeks prior to the first cycle, the patients would receive a comprehensive evaluation, including complete medical history, physical examination, BRT, serum biochemistry test, electrolytes, lactate dehydrogenase (LDH), electrocardiogram, position emission tomographycomputed tomography (PET-CT) or enhanced computed tomography (CT) or magnetic resonance imaging scanning for nasopharyngeal region and enhanced CT scanning for neck, chest and abdomen-pelvis, and nasopharyngeal laryngoscopy. The above examinations were repeated in one month after CCRT, one month after consolidated LVDP, and every 3-6 months during follow-up.

\section{Assessment}

According to non-Hodgkin's lymphoma Efficacy Evaluation Criteria [21], treatment response was assessed. ORR included CR and PR, while SD and PD were judged to be invalid. OS defined as the time from enrollment to the end of follow-up or death, and PFS defined as the time from enrollment to the end of follow-up or discovery of disease progression or relapse. Definition and grading standards of adverse reactions were referred to the Common Terminology Criteria for Adverse Events version 3.0 developed by American National Cancer Institute.

\section{Statistical analysis}

SPSS 16.0 (SPSS Japan Inc, Tokyo, Japan) was used. Kaplan-Meier method was used to calculate PFS and OS. Survival curves were compared by Log rank test. $P$ value of $<0.05$ was considered statistically significant.

\section{Authors' contributions}

Liqun Zou designed the research; Li Zhang and Ming Jiang wrote the paper; Ming Jiang, Li Zhang, Li Xie, Hong Zhang, Yu Jiang, Wei-ping Liu, Wen-yan Zhang, Rong Tian, Yao-tiao Deng, Sha Zhao, Li-qun Zou performed research; Weiping Liu and Wenyan Zhang did the pathologic review; and Li Zhang and Li Xie analyzed results and made the figures.

\section{ACKNOWLEDGMENTS}

The authors thank Lu Dai for excellent clinical data management.

\section{CONFLICTS OF INTERESTS}

This work has funding support from West China Hospital, Chengdu, China. The authors declare on competing financial interests.

\section{REFERENCES}

1. Harris NL, Jaffe ES, Diebold J, Flandrin G, MullerHermelink HK, Vardiman J, Lister TA, Bloomfield CD. World Health Organization classification of neoplastic diseases of the hematopoietic and lymphoid tissues: report of the Clinical Advisory Committee meeting-Airlie House, Virginia, November 1997. J Clin Oncol. 1999; 17:3835-49.

2. Au WY, Ma SY, Chim CS, Choy C, Loong F, Lie AK, Lam CC, Leung AY, Tse E, Yau CC, Liang R, Kwong YL. Clinicopathologic features and treatment outcome of mature T-cell and natural killer-cell lymphomas diagnosed according to the World Health Organization classification scheme: a single center experience of 10 years. Ann Oncol. 2005; 16:206-14.

3. Sun J, Yang Q, Lu Z, He M, Gao L, Zhu M, Sun L, Wei L, Li M, Liu C, Zheng J, Liu W, Li G, Chen J. Distribution of lymphoid neoplasms in China: analysis of 4,638 cases according to the World Health Organization classification. Am J Clin Pathol. 2012; 138:429-34.

4. $\mathrm{Au}$ WY, Weisenburger DD, Intragumtornchai $\mathrm{T}$, Nakamura 
S, Kim WS, Sng I, Vose J, Armitage JO, Liang R, and International Peripheral T-Cell Lymphoma Project. Clinical differences between nasal and extranasal natural killer/Tcell lymphoma: a study of 136 cases from the International Peripheral T-Cell Lymphoma Project. Blood. 2009; 113:3931-37.

5. Oshimi K, Kawa K, Nakamura S, Suzuki R, Suzumiya J, Yamaguchi M, Kameoka J, Tagawa S, Imamura N, Ohshima K, Kojya S, Iwatsuki K, Tokura Y, et al. NK-cell neoplasms in Japan. Hematology. 2005; 10:237-45.

6. Vose J, Armitage J, Weisenburger D, and International T-Cell Lymphoma Project. International peripheral T-cell and natural killer/T-cell lymphoma study: pathology findings and clinical outcomes. J Clin Oncol. 2008; 26:4124-30.

7. Wang L, Wang ZH, Chen XQ, Li YJ, Wang KF, Xia YF, Xia ZJ. First-line combination of gemcitabine, oxaliplatin, and L-asparaginase (GELOX) followed by involved-field radiation therapy for patients with stage IE/IIE extranodal natural killer/T-cell lymphoma. Cancer. 2013; 119:348-55.

8. Kim SJ, Kim K, Kim BS, Kim CY, Suh C, Huh J, Lee SW, Kim JS, Cho J, Lee GW, Kang KM, Eom HS, Pyo HR, et al. Phase II trial of concurrent radiation and weekly cisplatin followed by VIPD chemotherapy in newly diagnosed, stage IE to IIE, nasal, extranodal NK/T-Cell Lymphoma: Consortium for Improving Survival of Lymphoma study. J Clin Oncol. 2009; 27:6027-32.

9. Yamaguchi $M$, Tobinai $K$, Oguchi $M$, Ishizuka $N$, Kobayashi Y, Isobe Y, Ishizawa K, Maseki N, Itoh K, Usui N, Wasada I, Kinoshita T, Ohshima K, et al. Phase I/II study of concurrent chemoradiotherapy for localized nasal natural killer/T-cell lymphoma: Japan Clinical Oncology Group Study JCOG0211. J Clin Oncol. 2009; 27:5594-600.

10. Jiang M, Zhang H, Jiang Y, Yang Q, Xie L, Liu W, Zhang W, Ji X, Li P, Chen N, Zhao S, Wang F, Zou L. Phase 2 trial of "sandwich" L-asparaginase, vincristine, and prednisone chemotherapy with radiotherapy in newly diagnosed, stage IE to IIE, nasal type, extranodal natural killer/T-cell lymphoma. Cancer. 2012; 118:3294-301.

11. Lee J, Suh C, Park YH, Ko YH, Bang SM, Lee JH, Lee DH, Huh J, Oh SY, Kwon HC, Kim HJ, Lee SI, Kim JH, et al. Extranodal natural killer T-cell lymphoma, nasal-type: a prognostic model from a retrospective multicenter study. $\mathrm{J}$ Clin Oncol. 2006; 24:612-18.

12. Li YX, Liu QF, Wang WH, Jin J, Song YW, Wang SL, Liu YP, Liu XF, Zhou LQ, Yu ZH. Failure patterns and clinical implications in early stage nasal natural killer/T-cell lymphoma treated with primary radiotherapy. Cancer. 2011; 117:5203-11.

13. Li YX, Yao B, Jin J, Wang WH, Liu YP, Song YW, Wang SL, Liu XF, Zhou LQ, He XH, Lu N, Yu ZH. Radiotherapy as primary treatment for stage IE and IIE nasal natural killer/T-cell lymphoma. J Clin Oncol. 2006; 24:181-89.

14. Wang B, Li XQ, Ma X, Hong X, Lu H, Guo Y.
Immunohistochemical expression and clinical significance of P-glycoprotein in previously untreated extranodal NK/Tcell lymphoma, nasal type. Am J Hematol. 2008; 83:79599.

15. Lee J, Cho SG, Chung SM, Ryu MR, Kim SH, Jang HS, Choi BO. Retrospective analysis of treatment outcomes for extranodal NK/T-cell lymphoma (ENKL), nasal type, stage I-IIE: single institute experience of combined modality treatment for early localized nasal extranodal NK/T-cell lymphoma (ENKL). Ann Hematol. 2013; 92:333-43.

16. Bi XW, Xia Y, Zhang WW, Sun P, Liu PP, Wang Y, Huang JJ, Jiang WQ, Li ZM. Radiotherapy and PGEMOX/GELOX regimen improved prognosis in elderly patients with earlystage extranodal NK/T-cell lymphoma. Ann Hematol. 2015; 94:1525-33.

17. Kim SJ, Yoon DH, Jaccard A, Chng WJ, Lim ST, Hong H, Park Y, Chang KM, Maeda Y, Ishida F, Shin DY, Kim JS, Jeong SH, et al. A prognostic index for natural killer cell lymphoma after non-anthracycline-based treatment: a multicentre, retrospective analysis. Lancet Oncol. 2016; 17:389-400.

18. Ito Y, Kimura H, Maeda Y, Hashimoto C, Ishida F, Izutsu K, Fukushima N, Isobe Y, Takizawa J, Hasegawa Y, Kobayashi H, Okamura S, Kobayashi H, et al. Pretreatment EBV-DNA copy number is predictive of response and toxicities to SMILE chemotherapy for extranodal NK/T-cell lymphoma, nasal type. Clin Cancer Res. 2012; 18:4183-90.

19. Wang ZY, Liu QF, Wang H, Jin J, Wang WH, Wang SL, Song YW, Liu YP, Fang H, Ren H, Wu RY, Chen B, Zhang $\mathrm{XM}$, et al. Clinical implications of plasma Epstein-Barr virus DNA in early-stage extranodal nasal-type NK/T-cell lymphoma patients receiving primary radiotherapy. Blood. 2012; 120:2003-10.

20. Wang H, Li YX, Wang WH, Jin J, Dai JR, Wang SL, Liu YP, Song YW, Wang ZY, Liu QF, Fang H, Qi SN, Liu XF, Yu ZH. Mild toxicity and favorable prognosis of high-dose and extended involved-field intensity-modulated radiotherapy for patients with early-stage nasal NK/T-cell lymphoma. Int J Radiat Oncol Biol Phys. 2012; 82:111521.

21. Cheson BD, Horning SJ, Coiffier B, Shipp MA, Fisher RI, Connors JM, Lister TA, Vose J, Grillo-López A, Hagenbeek A, Cabanillas F, Klippensten D, Hiddemann W, et al. Report of an international workshop to standardize response criteria for non-Hodgkin's lymphomas. J Clin Oncol. 1999; $17: 1244$. 